\title{
A Rare Case of Transitional Cell Carcinoma of the Sino Nasal Tract: A Diagnosis with Multiple Synonyms. Review of Literatures
}

\author{
Kasim Saif Kasim Aljanabi ${ }^{1 *}$ and Salma Mohammed Hamed AL Sheibani ${ }^{2}$ \\ ${ }^{1}$ ENT Specialist, IBRA Hospital, Oman
}

${ }^{2}$ ENT and Head \& Neck Surgery Senior Consultant Head of ENT Department AL Nahdha Hospital, Sultanate of Oman, Oman

*Corresponding author: Kasim Saif Kasim Aljanabi, MB Ch B (Baghdad), MS (ORL-HNS) Malaysia, ENT specialist Ibra hospital, Oman

\begin{abstract}
Malignant sinonasal carcinomas are a rare entity comprising less than $1 \%$ of all cancers and around 3\% of all head and neck malignancies seen in humans. Among this $15-20 \%$ are transitional cell carcinoma also known as non-keratinizing carcinomas of sinonasal tract or cylindrical cell carcinoma or Schneiderian carcinoma or Ringertz carcinoma or respiratory epithelial carcinoma. We are reporting a case of 72 years old gentleman presented with CVA and during brain CT a right nasal mass lesion found incidentally. Endoscopy assisted biopsy was taken which revealed sinunasal carcinoma of transitional type. Very few reported cases were found upon searching the English literature. A possible reason could be histopathological challenges or the multiple synonyms of this tumor.
\end{abstract}

Keywords: Transitional Cell Carcinoma; Nonkeratinizing Carcinoma; Schneiderian Carcinoma; Cylindrical Cell Carcinoma; Ringertz Carcinoma; Respiratory Epithelial Carcinoma

\section{Case History}

A 72 year old hypertensive gentleman presented with left hemiplegia and diagnosed with right parietal lobe infarct by CT scan and noted soft tissue density mass lesion occupying the right nasal cavity. Upon history noted to have progressive right nasal blockage for few months prior to presentation associated with occasional nasal blood stained discharge and epiphora for few months. Family noted right sided facial swelling over the cheek area. He denied diplopia, reduce vision, restricted mouth opening, neck swelling. On examination elderly man bed ridden with left sided hemiplegia. There is obvious right facial swelling over the right cheek area extending to the floor of the eye there was no proptosis and skin overlying was normal. Nasal examination on the right side was totally occluded by the mass. Another ENT exam was unremarkable. Contrast enhanced CT scan (Figure 1) revealed 64X36X43 mm enhanced soft tissue density epicenter at the right medial wall of the maxillary sinus extending to the right nasal cavity, right ethmoid sinus and causing erosion of the medial wall of the orbit with periorbital fat involvement. Extra ocular muscles were normal. Posteriorly it extends till the nasopharynx. Anteriorly it was encroaching to the subcutaneous tissue of the skin. There was no cervical lymphadenopathy. Endoscopic guided biopsy reveled sinonasal carcinoma of transitional type. Chest x-ray and ultrasound abdomen revealed no distant metastasis so clinical and radiological staging was T4aN0M0. He was planned for combined modality treatment as total maxillectomy with wide local skin excision and free flap reconstruction with palatal prosthesis and post-operative chemo-radiotherapy but in view of his general condition with nonfitness for GA family refused surgical intervention and patient was referred to oncology for palliative options.

\section{Discussion}

Transitional cell carcinoma of the sinonasal tract is a rare entity. The annual incidence of malignant sinonasal carcinoma is 3.5 per 100,000 population. Muir CS, et al. [1] Of this $15-20 \%$ is transitional carcinoma Robin, et al. [2]. According to the WHO classification, it has many synonyms including, Schneiderian carcinoma, cylindrical 
cell carcinoma, Ringertz carcinoma, and respiratory epithelial carcinoma, Plich BZ, et al. [3] as the tumor is composed of malignant proliferating cells derived from the sinonasal respiratory (Schneiderian) epithelium [4]. The name cylindrical cell carcinoma was first coined by Ringertz [5] and was recommended as the preferred term by Shanmugaratnam in the WHO classification of 1991. [6] Sinonasal carcinoma (Squamous cell carcinoma and adenocarcinoma) are strongly associated with environmental factors, including tobacco, alcohol, and occupational exposure (e.g. to heavy metal, nickel, and chromium), and with workers in the leather, textile, and wood industries [3,7-10]. Sinonasal tract malignancies most commonly affect the maxillary sinus (about $60 \%$ ), followed by the nasal cavity (about 22\%), ethmoid sinus (about 15\%), and frontal and sphenoid sinuses (3\%) [3,8-10]. In this case, no association with the risk factors was found. A strong etiological relationship between transitional cell carcinoma and the human papilloma virus (HPV) has been suggested by some recent studies $[11,12]$. Cervical lymph node metastasis develops in up to $20 \%$ of the patients, with rare distant metastasis $[3,10]$. In our case there was no cervical lymphadenopathy. Treatment depends on TNM staging [3]. T1 and T2 nasal tumors are treated by surgical resection, while $\mathrm{T} 3$ and $\mathrm{T} 4$ tumors receive postoperative radiotherapy. Various surgical approaches like lateral rhinotomy or medial maxillectomy or an end bloc ethmoidectomy are done for superior and lateral nasal cavity carcinomas [13].

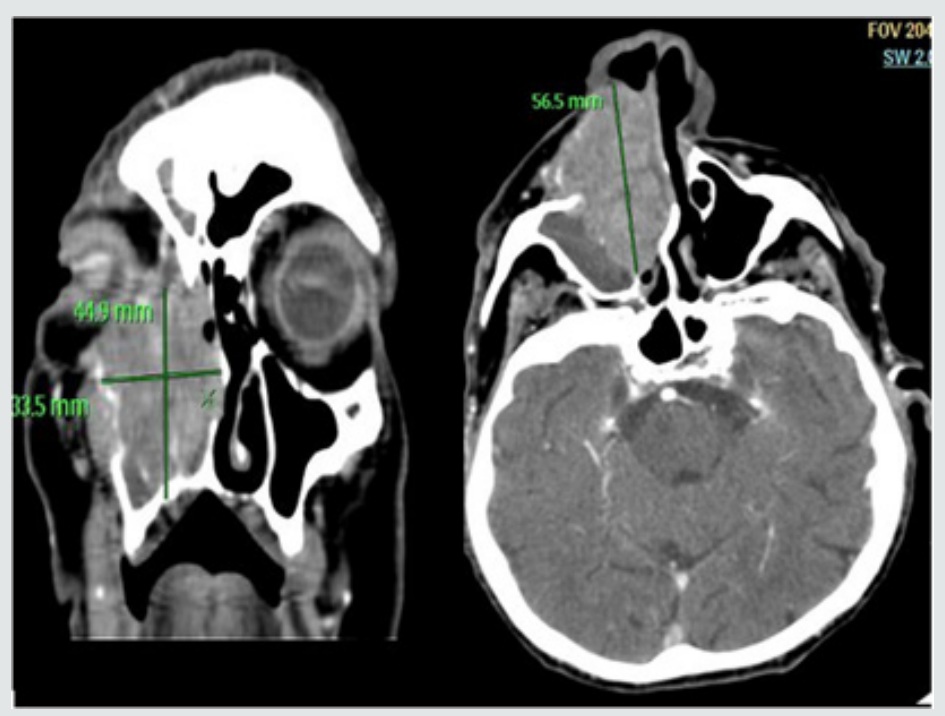

Figure 1: Contrast computed tomography scan, coronal section (right) axial section (left). A predominantly homogeneously enhancing mass is seen expanding the right nasal cavity, with minimal bulging of the nasal septum to the left. The epicenter of the mass appears to be from medial wall of the right maxillary sinus extending to ethmoid sinus. Thinning and displacement of ipsilateral lamina papyracea. No evidence of extraocular muscles involvement within the right orbit. Obliteration of the right maxillary ostium and infundibulum by the inferolateral aspect of the mass can be observed. Retained fluid within the right frontal \& maxillary sinuses from osteomata complex obstruction is evident.

Upon literature review in a series reported by Osborn in 1970 there were 57 cases of transitional cell carcinomas seen and treated in the Royal National Throat and Ear Hospital between 1948 and 1968 accounting for approximately $20 \%$ of all carcinomas of the nose and sinuses [14]. A review by Robin et al. in 1979 illustrated a series obtained from registrations in the Birmingham Regional Cancer Registry from 1957 to 1972 inclusive of only 48 cases of transitional cell carcinomas constituting merely $7.7 \%$ of all malignant tumors of the nose and paranasal sinuses [2]. Manivel et al. [15] in 1986 reported two cases of transitional (cylindric) cell carcinoma with endodermal sinus tumor-like features of the nasopharynx and paranasal sinuses. In 2000, CalderonGarciduenas et al. published their series obtained from a major oncology hospital in metropolitan Mexico City from 1976-1997 which listed Schneiderian carcinoma as one of the diagnosis in their 256 patients [16]. El Mofty and Lu [11] in 2005 reported only eight cases of nonkeratinizing carcinomas (NKCa) retrieved from the Department of Pathology and Immunology at Washington University School of Medicine, St. Louis Missouri, though they did not specify when they were diagnosed. Robin et al. found a difference in the mean age of presentation between men and women in NKCa which was 57.8 years and 70.4 years, respectively [2]. This difference was statistically significant and was greater than in other histological groups. Another observation was that NKCa in men carried a better prognosis than in women where the five-year survival rates were $40 \%$ and $13 \%$ respectively. A recent study has also shown that NKCas of the sinonasal tract have a higher prevalence of high risk HPV DNA than other types of carcinomas in this region [11]. In conclusion, sinonasal transitional cell carcinoma is a rare malignancy of the nose and paranasal sinuses and should be recognized as a distinct clinicopathologic entity to determine the best treatment modality and to better predict the outcome of treatment. Synonyms of this tumor should be standardized to avoid confusion and misdocumentation. 


\section{References}

1. Muir CS, Nectoux J (1980) Descriptive epidemiology of malignant neoplasms of nose, nasal cavities, middle ear and accessory sinuses. Clin Otolaryngol Allied Sci 5(3): 195-211.

2. Robin P, Powell DJ, Stansbie JM (1979) Carcinoma of the nasal cavity and paranasal sinuses: Incidence and presentation of different histologic types. Clin Otolaryngol Allied Sci 4(6): 431-456.

3. Pilch BZ, Bouquot J, Thompson LD (2005) Squamous cell carcinoma. In: Barnes L, Eveson JW, Reichart P, Sidransky D, (Eds.), World Health Organization classification of tumors. Pathology and genetics of head and neck tumors. Lyon: IARC Press, p. 157.

4. Prakash SB, Nishan (2013) A rare malignancy of sinonasal tract transitional cell carcinoma: A case report. J Evol Med Dent Sci 2: 694650.

5. Ringertz N (1938) Pathology of malignant tumors arising in the nasal and paranasal cavities and maxilla. Acta Otolaryngol Suppl 27: 314-322.

6. Shanmugaratnam K (1991) WHO histological typing of tumors of the upper respiratory tract and ear. Springer $2^{\text {nd }}$ Ed, Berlin, Heidelberg, New York, p3.

7. Luce D, Leclerc A, Bégin D, Demers PA, Gérin M, et al. (2002) Sinonasal cancer and occupational exposures: A pooled analysis of 12 casecontrol studies. Cancer Causes Control 13(2): 147-157.

8. McNicoll W, Hopkin N, Dalley VM, Shaw HJ (1984) Cancer of the paranasal sinuses and nasal cavities. Part II. Results of treatment. J Laryngol Otol 98: 707-718.
9. Hopkin N, McNicoll W, Dalley VM, Shaw HJ (1984) Cancer of the paranasal sinuses and nasal cavities. Part I. Clinical features. J Laryngol Otol 98: 585-595.

10. Jackson RT, Fitz Hugh GS, Constable WC (1977) Malignant neoplasms of the nasal cavities and paranasal sinuses: A retrospective study. Laryngoscope 87(5 Pt 1): 726-736.

11. El Mofty SK, Lu DW (2005) Prevalence of high-risk human papillomavirus DNA in non-keratinizing (transitional cell) carcinoma of the sinonasal tract. A distinct clinicopathologic and molecular disease entity. Am J Surg Pathol 29(10):1367-1372.

12. Carrau RL, Segas J, Nuss DW, Snyderman CH, Janecka IP, et al. (1999) Squamous cell carcinoma of the sinonasal tract invading the orbit. Laryngoscope 109(2 Pt 1): 230-235.

13. Thompson LD (2006) Sinonasal carcinomas. Curr Diagn Pathol 12: 405413.

14. Osborn DA (1970) Nature and behavior of transitional tumors of the upper respiratory tract. Cancer 25(1): 50-60.

15. Manivel C, Wick MR, Dehner LP (1986) Transitional (cylindric) cell carcinoma with endodermal sinus tumor-like features of the nasopharynx and paranasal sinuses. Clinicopathologic and immunohistochemical study of two cases. Arch Pathol Lab Med 110(3): 198-202.

16. Calderon Garciduenas L, Delgado R, Calderon Garciduenas A, Meneses A, Ruiz LM, et al. (2000) Malignant neoplasms of the nasal cavity and paranasal sinuses: a series of 256 patients in Mexico City and Monterrey. Is air pollution the missing link? Otolaryngol Head Neck Surg 122(4): 499-508.

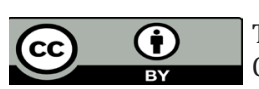

This work is licensed under Creative Commons Attribution 4.0 License

To Submit Your Article Click Here: Submit Article

DOI: $10.32474 /$ SJO.2019.01.000122

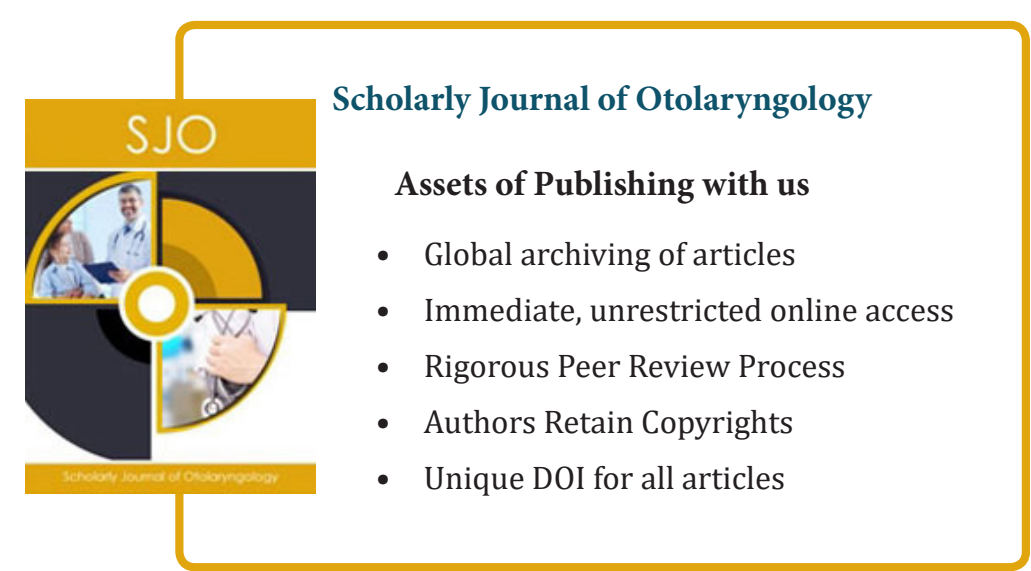

